\title{
Fatigue life prediction of z-fibre pinned composite laminate under the mode I loading
}

\author{
Suchao Tang ${ }^{\mathrm{a}}$, Stuart Lemanski ${ }^{\mathrm{a}}$, Xiang Zhang, ${ }^{\mathrm{a}, *}$, David Ayre ${ }^{\mathrm{b}}$ \\ ${ }^{a}$ Centre for Manufacturing and Materials Engineering, Coventry University, Coventry, CV1 5FB, United Kingdom \\ ${ }^{\mathrm{b}}$ Enhanced Composites and Structures Centre, School of Aerospace, Transport and Manufacturing, Cranfield \\ University, MK43 OAL, United Kingdom \\ *Corresponding author. Email address: xiang.zhang@ coventry.ac.uk
}

\begin{abstract}
A hybrid method is presented combining linear elastic fracture mechanics with nonlinear damage mechanics that can predict the fatigue crack growth rate in z-fibre pinned composites under mode I loading. The strain energy release rate is evaluated using the virtual crack closure technique via finite element analysis. Cohesive elements are used in the pinned region to represent the crack bridging force generated by the pins. The reduction of the pins' bridging force under the fatigue loading is accommodated by applying a degradation law, based on damage mechanics with empirical fitting parameters. A modified degradation law is proposed which is capable of accumulating fatigue damage under varying crack opening displacement ranges experienced by the pins during fatigue loading. Fatigue testing was performed with a $\mathrm{z}$ pinned double cantilever beam at two different values of applied displacement amplitude. The predictions show reasonably good agreement with the test results in terms of the fatigue crack propagation rate and fatigue life.
\end{abstract}

Keywords: Carbon fibre composites; through-thickness reinforcement; z-fibre; fatigue life prediction; finite element analysis 


\begin{tabular}{|c|c|c|c|}
\hline \multicolumn{4}{|c|}{ Nomenclature } \\
\hline$a$ & debond crack length & $P_{d}, P_{d 0}$ & current, initial (static) peak debond force \\
\hline$A_{\text {pin }}$ & cross-sectional area of z-pin & $P_{f}, P_{f 0}$ & current, initial (static) peak frictional force \\
\hline$c, d$ & $\begin{array}{l}\text { fitting parameter of pin's degradation } \\
\text { law, eq. } 4\end{array}$ & $q$ & $\begin{array}{l}\text { ratio of cyclic displacement amplitude to } \\
\text { static pull-out displacement, eq. } 5\end{array}$ \\
\hline $\begin{array}{l}C, m \\
\mathrm{~d} a / \mathrm{d} N\end{array}$ & $\begin{array}{l}\text { Paris law constants } \\
\text { fatigue crack growth rate }\end{array}$ & $r$ & $\begin{array}{l}\text { ratio of cyclic mean displacement to static } \\
\text { pull-out displacement, eq. } 6\end{array}$ \\
\hline$d_{\mathrm{Pmax}}$ & $\begin{array}{l}\text { displacement of DCB at peak static } \\
\text { load }\end{array}$ & $T_{\mathrm{d}}, T_{\mathrm{f}}$ & $\begin{array}{l}\text { debond, frictional traction strength of } \\
\text { cohesive element at pin location }\end{array}$ \\
\hline$D, D_{\text {acc }}$ & $\begin{array}{l}\text { reduction, accumulated reduction of } \\
\text { pin's bridging force }\end{array}$ & $\alpha, \beta$ & $\begin{array}{l}\text { fitting parameter of pin's degradation law, } \\
\text { eq. } 4\end{array}$ \\
\hline$D_{d}, D_{\mathrm{f}}$ & $\begin{array}{l}\text { accumulated reduction factor of pin's } \\
\text { bridging force by debonding or } \\
\text { frictional degradation law }\end{array}$ & $\begin{array}{l}\delta \\
\delta_{a}, \delta_{m}\end{array}$ & $\begin{array}{l}\text { current displacement on a pin row } \\
\text { amplitude, mean displacement on a pin row }\end{array}$ \\
\hline$G$ & strain energy release rate & $\delta_{d}, \delta_{d 0}$ & $\begin{array}{l}\text { current (fatigue), initial (static) debond } \\
\text { displacement on a pin row }\end{array}$ \\
\hline \multirow{3}{*}{$\begin{array}{l}G_{\text {IC }} \\
i \\
n_{\text {eff }}, n_{\text {nom }}\end{array}$} & laminate mode I fracture toughness & & current (fatigue), initial (static) displacement \\
\hline & $\begin{array}{l}\text { iteration number }(i=1,2, \ldots, k) \\
\text { effective, nominal pin number in a pin }\end{array}$ & $\delta_{f}, \delta_{f 0}$ & at peak frictional force \\
\hline & row & $\delta_{\text {pull }}$ & $\begin{array}{l}\text { current fatigue pull-out displacement on a } \\
\text { pin row }\end{array}$ \\
\hline $\begin{array}{l}N, \Delta N \\
N_{\mathrm{f}}\end{array}$ & $\begin{array}{l}\text { current, increment number of cycles } \\
\text { number of cycles to final failure }\end{array}$ & $\delta_{\text {pull_0}}$ & $\begin{array}{l}\text { initial pull-out displacement (static) on a pin } \\
\text { row }\end{array}$ \\
\hline
\end{tabular}

\section{Introduction}

The use of z-fibres (z-pins) is an effective method for improving the interlaminar fracture toughness of composite laminates. Experimental studies have been carried out to understand the bridging effect of z-pins under static and impact loading conditions [1-4]. The traction forces generated by z-pins are affected by many factors, including the mechanical and physical properties of the pins themselves, the manufacturing conditions (e.g. curing temperature, incline angle of the z-pins), and the interfacial conditions between z-pins and the composite material. Many constitutive models have been presented in published literature, which describe the traction load vs. crack opening displacement relation for single pins. These include analytical models [5-7] and empirical models [8,9]. Due to the complexity of the z-pin bridging nature, numerical models have also been established as an alternative solution [10-12]. Those 
constitutive models have been implemented in the finite element (FE) analysis to simulate zpinned structures under static loading [6, 8-11, 13-15]. Early approaches applied nonlinear spring elements on the delamination surfaces to model the bridging behaviour of z-pins $[6,8$, 9, 13]. Recently, cohesive zone elements at discrete pin locations have been used to model zpinned laminates of the double cantilever beam (DCB) geometry under mode I loading, by deriving the cohesive parameters from a mesomechanical model of the pin pull-out process [10]. This approach was then extended to the mode II [11] and mixed mode [14,15] loading conditions.

The benefits of z-pins are not limited to the static load cases. When z-pinned laminates are subjected to cyclic loading, z-pins also form a large-scale crack bridging zone to retard fatigue crack growth. The effect has been experimentally studied for cyclic loading under the mode I [16-19], mode II [19-22] and mixed mode [23] conditions. Work in [19] shows that z-pinning is more effective in resisting the mode I fatigue cracking, due to differences in the bridging mechanism and failure modes (e.g. pin debonding followed by frictional pull-out for mode I, compared to shear-induced pin rupture for mode II). A study of mixed mode cyclic loading revealed that reducing the mode I and increasing the mode II load component led to a change in the fatigue failure mechanism from pin pull-out to shear deformation and fracture of the pins [23]; hence the reduction of the beneficial effect of pinning with increased mode II.

Zhang et al. [16] proposed a micromechanical model for calculating the reduction of bridging tractions (debonding and friction pull-out forces) under a mode I fatigue loading, based on the fatigue data and experimental observations. The degradation law was then applied to a fracture energy based analytical model to predict the fatigue life of a z-pinned double cantilever beam 
(DCB). However, experimental validation of the predictive model was not performed, and the proposed degradation law did not account for the variable displacement amplitude that the pins had experienced when they were in the wake of the propagating crack. The effect of an applied displacement amplitude was investigated experimentally in [26] using a phenomenological model to describe the degradation of energy dissipation, considering both amplitude and mean pull-out displacement of a pin. However, the pin's debonding phase was not considered in the model, which is an important mechanism for the z-pinned laminate subjected to relatively small load amplitudes in fatigue. Furthermore, the crack opening displacement applied on those pins in the crack wake is variable during the fatigue crack growth process; hence a method for accumulating pins' fatigue degradation under variable amplitude loading is desirable.

Few papers can be found that address the prediction of the response of z-pinned structures under fatigue loading. It requires a thorough understanding of single pin bridging behaviour under cyclic loading. Recent investigations $[16,26]$ show that the pin's surface and surrounding resin are gradually worn under the fatigue loading. Therefore, the pin bridging force is degraded with increasing load cycles. This degradation of the pin bridging force must be modelled and included in the analysis for predicting the fatigue life of a z-pinned laminate.

In this work a degradation law is proposed to describe the debonding and frictional degradation of the z-pin bridging force under a mode I fatigue load based on a damage mechanics approach with empirical fitting parameters. The proposed degradation law also considers the effect of the changing amplitude of the crack opening displacement when the crack bridging pins are in the crack wake. The fatigue degradation law of a single pin is then implemented in a fracture mechanics model to predict the fatigue life of a z-pinned DCB. In the model, the strain energy 
release rate is calculated by the virtual crack closure technique (VCCT) by finite element analysis, and the pin bridging force and its fatigue degradation is modelled by cohesive failure elements.

\section{Prediction strategy and approach}

\subsection{Procedure}

Finite element analysis (FEA) was used for crack extension modelling and stain energy release rate calculation. Fatigue crack growth was predicted using the FEA result in conjunction with measured crack growth rate in unreinforced laminates (no z-pins). The procedure is illustrated in Fig. 1 and key steps are as follows:

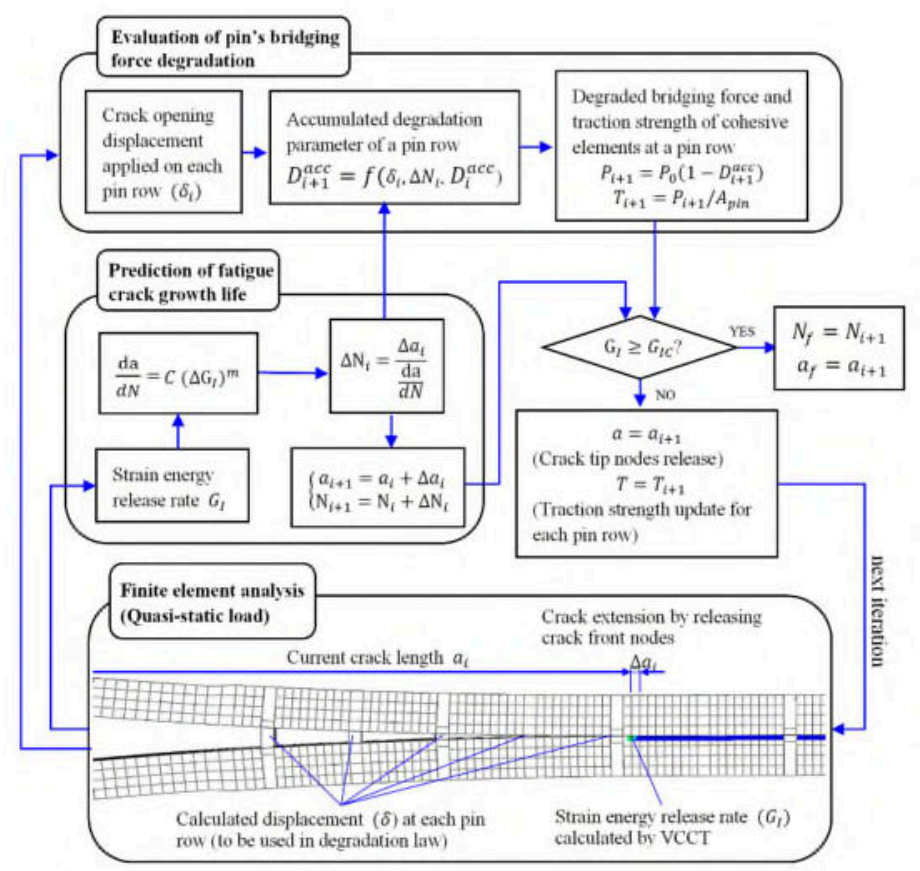

Fig. 1 Procedure for predicting fatigue crack growth life of z-pinned laminate under mode I load.

- Experimental testing of unreinforced DCB specimens to generate the material's mode I fatigue crack growth rate data.

- Calculating the strain energy release rate as function of the crack length under quasi-static load and a prescribed crack extension path.

- Modelling z-pin bridging force by cohesive elements at pin locations; cohesive model parameters are degraded with cyclic load. Since the bridging force degradation is also 
affected by the crack opening displacement, pins in different locations in the bridging zone can experience different levels of degradation, even though they have been subjected to the same fatigue load history.

- Calculating fatigue crack growth life by integrating the material's Paris law between the initial and final crack lengths.

\subsection{Model description}

A z-pinned double cantilever beam (DCB) was modelled (Fig. 2) under quasi-static load to calculate the strain energy release rate vs. crack extension, using the ABAQUS software package. The Virtual Crack Closure Technique (VCCT) is used to calculate the strain energy release rate (SERR) originating from the failure of the adhesive bond, and the Cohesive Zone Method (CZM) is used to model the pin's stetching, debonding and pullout phases. Due to the geometric symmetry, only half of the DCB is modelled with appropriate boundary conditions.

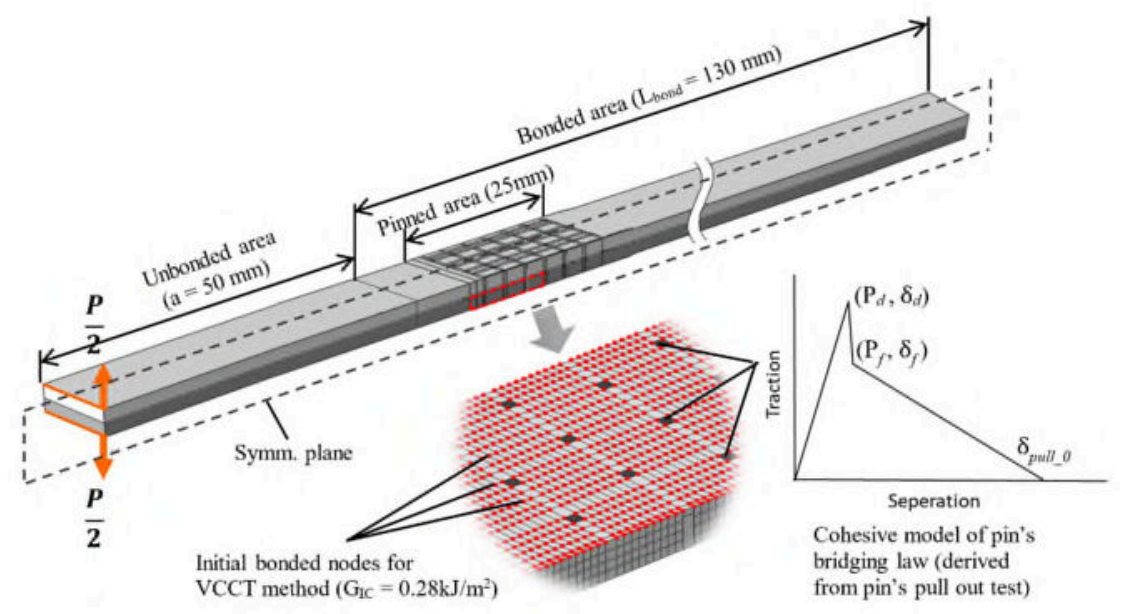

Fig. 2 FE model for half of DCB specimen; inserts show the bond interface and pins, and a tri-linear response of pin traction force vs. displacement relation to be used in the FE model

Fracture of the adhesive bond is governed by the fracture toughness $\left(G_{\mathrm{IC}}\right)$ of the laminate material (matrix). The pinned locations have enhanced toughness, which can be described by the pin's traction force vs. displacement relation that can be described by a tri-linear expression given in eq. (1) (and shown graphically in the Fig. 2 insert). The first stage represents the pin's 
elastic stretching, which is followed by debonding (second stage), and frictional pull-out of fully debonded pin (final stage).

$$
P=\left\{\begin{array}{cc}
\frac{\delta}{\delta_{d}} P_{d} & \left(0 \leq \delta \leq \delta_{d}\right) \\
\frac{\delta_{f}-\delta}{\delta_{f}-\delta_{d}} P_{d}+\frac{\delta-\delta_{d}}{\delta_{f}-\delta_{d}} P_{f} & \left(\delta_{d} \leq \delta \leq \delta_{f}\right) \\
P_{f}+\frac{\delta_{f}-\delta}{\delta_{\text {pull }}-\delta_{f}} P_{f} & \left(\delta_{f} \leq \delta \leq \delta_{\text {pull }}\right)
\end{array}\right.
$$

where $P$ is the bridging force, $P_{\mathrm{d}}$ the maximum debonding force, $P_{\mathrm{f}}$ the maximum friction force, and $\delta, \delta_{d}, \delta_{f}$ are the corresponding displacements, and $\delta_{p u l l}$ the pin's pull-out displacement. The crack propagation rate is affected by the pin quality, reflected by the pin bridging parameters used in the models. To account for the variations, the prediction method assumed that each pin row has its own bridging law parameters, being calculated from the actual peak debond and frictional loads for each pin row based on a summation of damaged, imperfect and missing pins as observed in the tests. An imperfect or damaged pin was counted as a half pin, in terms of the bridging force value. Thus, the effective peak bridging force in each pin row was calculated as:

$$
P_{d}=\frac{n_{e f f}}{n_{n o m}} P_{d 0} \text { or } P_{f}=\frac{n_{e f f}}{n_{n o m}} P_{f 0}
$$

where $n_{\text {nom }}$ is the nominal number of pins in a pin row as manufactured, $n_{\text {eff }}$ is the number of effective pins in a pin row (based on post-failure examination), $P_{d}$ and $P_{f}$ now refer to the effective peak debond and frictional loads, respectively.

Two extreme scenarios are used to predict the upper and lower bounds of fatigue life. The first case assumed a perfect condition that every pin is perfectly inserted, with $n_{\text {eff }}=n_{\text {nom }}=7$ in the specimen. The second case used the worst pin condition as observed after the static load tests (specimens S1-S3), with an average effective pin number $n_{\mathrm{eff}}=5$.

\subsection{Degradation law of single pin bridging force under fatigue loading}


There are currently two published papers $[16,26]$ proposing possible pin degradation laws based on experimental tests. However, both laws $[16,26]$ have limitations (as discussed in the Introduction) and thus cannot be used directly in the fatigue prediction procedure of this study. A new degradation law is proposed in this paper based on a damage mechanics model originally proposed by Peerlings et al [25]. The model in [25] was aimed at describing the damage model variables in the high-cycle fatigue regime within the interface elements:

$$
D=-\frac{1}{\alpha} \ln \left(1-\frac{2 \alpha c}{\beta+1} \varepsilon_{a}^{\beta+1} N\right)
$$

where $\alpha, \beta$ and $c$ are material parameters at a constant strain amplitude $\varepsilon_{a}$.

To account for both cyclic displacement amplitude and mean displacement, a modified degradation law is proposed for this paper:

$$
D=-\frac{1}{\alpha} \ln \left(1-\frac{2 \alpha c}{\beta+1} N q^{\beta+1} r^{d}\right)
$$

where $\alpha, \beta, c$ and $d$ are material parameters, $q$ and $r$ are calculated by

$$
\begin{aligned}
& q=\frac{\delta_{a}}{\delta_{\text {pull }}} \text { or } q=\frac{\delta_{a}}{\delta_{d}} \\
& r=\frac{\delta_{m}}{\delta_{\text {pull }}} \text { or } r=\frac{\delta_{m}}{\delta_{d}}
\end{aligned}
$$

where $\delta_{a}$ and $\delta_{m}$ are respectively the cyclic displacement amplitude and mean displacement acting on a pin row, $\delta_{d}$ is the maximum debond displacement (debond degradation law), and $\delta_{\text {pull }}$ is the pin's maximum displacement under the static pull-out test (frictional degradation law). The pin length effect can be normalised using the maximum displacement, therefore this law can be used for modelling different pin lengths.

The fitting parameters $\alpha, \beta, c$ and $d$ for the debonding and frictional degradation law (eq. 4) are calculated based on the experimental test data in $[16,26]$ (Fig. 3) by a numerical fitting code [28], and are listed in Table 2. 
The normalized residual peak debond force and friction forces $\left(P_{\mathrm{d}} / P_{\mathrm{d} 0}, P_{\mathrm{f}} / P_{\mathrm{f} 0}\right)$ were then used to find the accumulated bridging force reduction parameters, $D_{\mathrm{d}}$ (debonding dominance) and $D_{\mathrm{f}}$ (friction dominance) by the debonding and frictional degradation laws:

$$
\begin{aligned}
& D_{d}=1-P_{d} / P_{d 0} \\
& D_{f}=1-P_{f} / P_{f 0}
\end{aligned}
$$

The proposed degradation law was used to describe the trend for the debonding and frictional reduction of pin bridging force under varying crack opening displacement amplitudes.
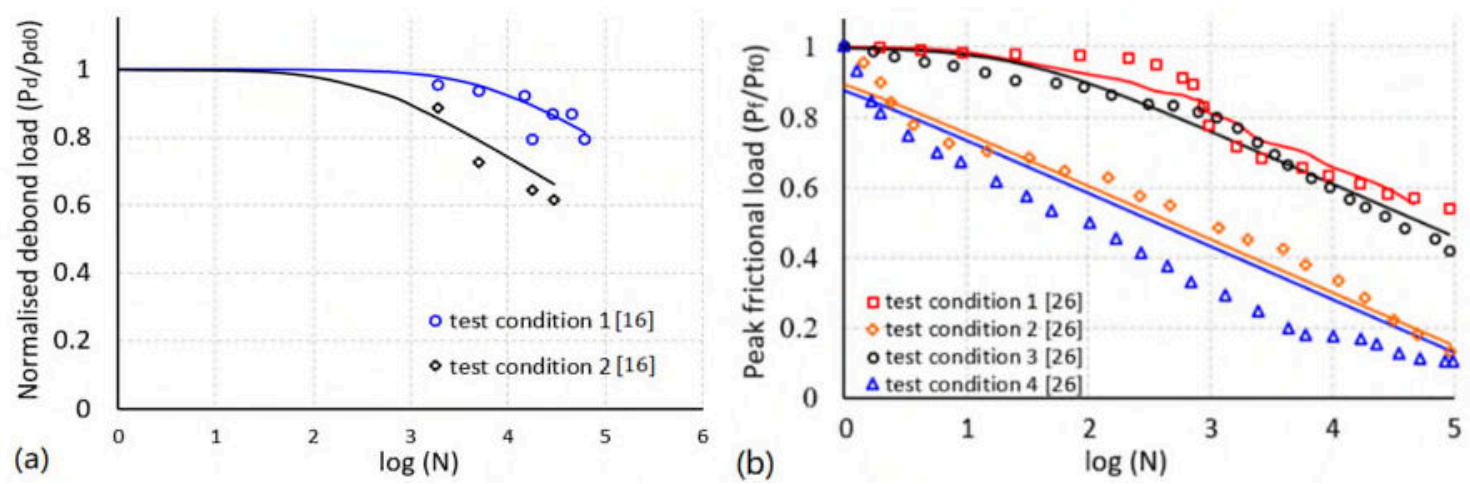

Fig. 3 Degradation law fitting: (a) debonding dominance test in [16] under two different sets of amplitude and mean displacement, (b) frictional dominance test in [26] under four different sets of amplitude and mean displacement. Test conditions in $[16,26]$ are given in Table 1 . The best fitted lines for the test data are used for determining the fitting parameters in eq. (4).

Table 1. Summary of displacement controlled fatigue tests in $[16,26]$

\begin{tabular}{llllll}
\hline Test condition & \multicolumn{3}{c}{$\begin{array}{l}\text { Experiment input displacement } \\
(\mathrm{mm})\end{array}$} & \multicolumn{2}{c}{$\begin{array}{l}\text { Cyclic displacement } \\
\text { ratios (eqs. 5-6) }\end{array}$} \\
& $\delta_{a}$ & $\delta_{m}$ & $\delta_{d}$ & $q$ & $r$ \\
\hline Debonding ref [16] & & & & & \\
Test 1 & 0.25 & 0.16 & 0.56 & 0.45 & 0.275 \\
Test 2 & 0.41 & 0.25 & 0.56 & 0.72 & 0.44 \\
Frictional ref [26] & & & $\delta_{\text {pull }}$ & & \\
Test 1 & 0.1 & 0.15 & 4.5 & 0.022 & 0.033 \\
Test 2 & 1.6 & 1.5 & 4.5 & 0.355 & 0.333 \\
Test 3 & 0.1 & 3 & 4.5 & 0.022 & 0.667 \\
Test 4 & 1.6 & 3 & 4.5 & 0.355 & 0.667 \\
\hline
\end{tabular}

Table 2 Fitting parameters for degradation law, eq. (4)

\begin{tabular}{lllll}
\hline & $\alpha$ & $\beta$ & $c$ & $d$ \\
\hline Debonding phase (data from [16]) & -13.55 & 2.83 & 0.0105 & 2.56 \\
Frictional pullout (data from [26]) & -14.19 & 0.79 & 2.51 & 0.44 \\
\hline
\end{tabular}



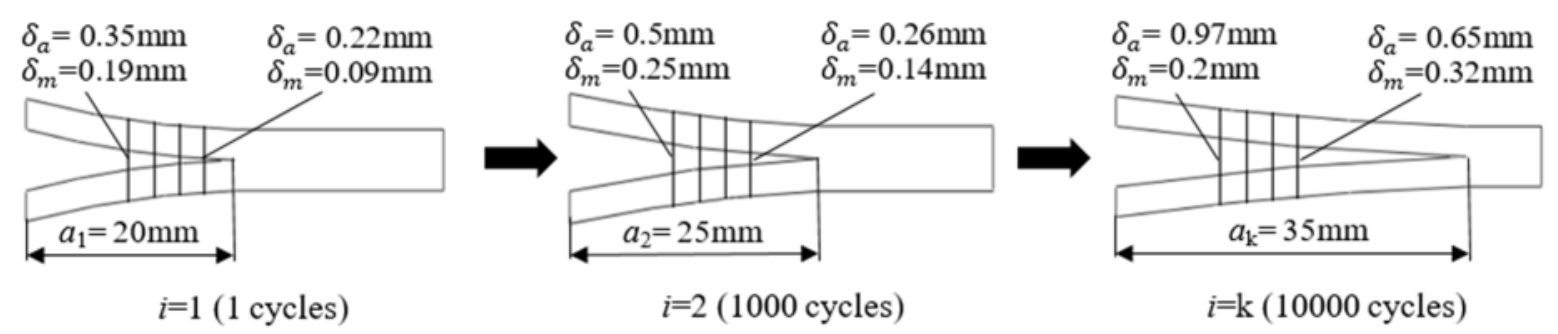

Fig.4 Crack opening displacement and its relation to the local amplitude and mean displacement $\left(\delta_{a}, \delta_{m}\right)$ on a particular pin row as the crack propagates under fatigue tests

Since the crack opening displacement applied on each pin row varies as the pin row position changes in the crack wake as illustrated in Fig. 4, equations (4-6) and fitting parameters in Table 2 were used in the proposed damage accumulation calculation. In the $i_{\text {th }}$ crack growth increment, the number of load cycles required $\left(N_{\mathrm{fi}}\right)$ under displacement condition $q_{i}$ and $r_{i}$ is obtained by setting $D=1$ and solving equation (4) for $N$, resulting in

$$
N_{f_{i}}=\frac{\left(1-e^{-\alpha}\right)}{\frac{2 \alpha c}{\beta+1} q_{i}^{\beta+1} r_{i}{ }^{d}}
$$

Using equation (9) for the fatigue life, equation (4) can be rewritten in terms of the relative number of cycles $N_{\mathrm{i}} / N_{\mathrm{fi}}$ (similar to the Miner's rule):

$$
D_{i}=-\frac{1}{\alpha} \ln \left(1-\left(1-e^{-\alpha}\right) \frac{N_{i}}{N_{f_{i}}}\right)
$$

If a pin row has experienced a series of damage $D_{\mathrm{i}}(i=1, \ldots, k)$ because of crack propagation, then the accumulated damage ratio $D_{\text {acc }}$ is calculated by

$$
D_{a c c}=-\frac{1}{\alpha} \ln \left(1-\left(1-e^{-\alpha}\right) \sum_{i=1}^{k} \frac{N_{i}}{N_{f_{i}}}\right)
$$

\subsection{Application of pin degradation law}

To simplify the single pin bridging behaviour under fatigue loading, the aforementioned method assumes that debonding occurs first, which is followed by pin frictional pullout. The peak debonding force degrades with increasing load cycles. The peak residual debonding load $P_{\mathrm{d}}$ can be calculated by equation (12) and using the parameters in Table 2. 


$$
P_{d}=\left(1-D_{d}\right) P_{d 0}
$$

According to the experimental data in [16], the slope of the elastic stretching portion of the curve does not change during fatigue testing, indicating that the elastic modulus of the pins was not affected by fatigue. Thus, the corresponding displacement to the peak residual debonding force, $\delta_{d}$, also reduces, and is proportional to $P_{\mathrm{d}}$ :

$$
\delta_{d}=\left(1-D_{d}\right) \delta_{d 0}
$$

The degradation of $P_{\mathrm{d}}$ and $\delta_{d}$ changes to the pin bridging law (load vs. displacement relation). A typical pin's bridging law change under fatigue load is illustrated by Fig. 5. The initial response and early degradation are shown in Figs. 5a and 5b. When the peak residual debond force $\left(P_{\mathrm{d}}\right)$ becomes lower than the peak friction force $\left(P_{\mathrm{f}}\right)$, the load vs. displacement relation changes to Fig. 5c, where the pin still experiences further debonding until the applied load overcomes the peak debond force, at which point the pin is fully debonded and the frictional pullout takes over as shown in Fig. 5d. After that, the peak friction force and failure displacement $\delta_{\text {pull }}$ degrade with increasing load cycles according to:

$$
\begin{gathered}
P_{f}=\left(1-D_{f}\right) P_{f 0} \\
\delta_{p u l l}=\left(1-D_{f}\right) \delta_{p u l l_{-} 0}
\end{gathered}
$$

where $D_{\mathrm{f}}$ is the accumulated damage parameter calculated by the friction degradation law.

At each crack growth increment, calculated values of crack opening displacement at each pin row and strain energy release rate at the crack front were used for the subsequent computation steps, i.e. numerical integration of fatigue crack growth and calculation of the pin bridging force degradation as illustrated in Fig. 1. The degraded pin's bridging law at the current crack increment was calculated by the procedure shown in Fig. 6 . All calculations were performed by using the Microsoft Excel tool. Finally, updated bridging laws for each pin row were manually 
transferred to an ABAQUS input file for the simulation of the next crack increment.
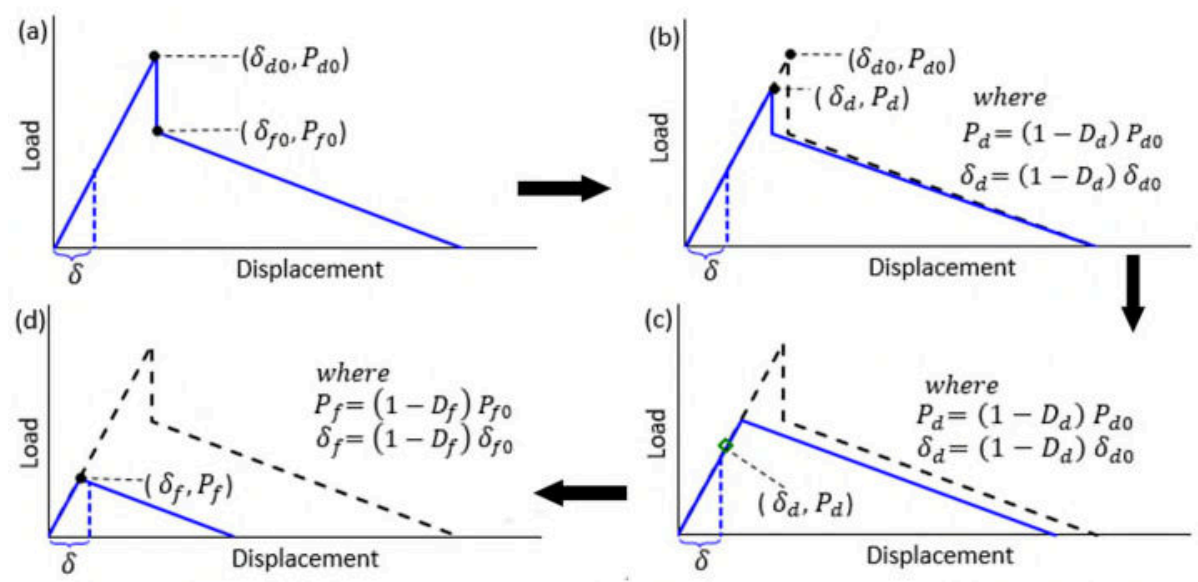

Fig. 5 Typical pin's bridging law evolution under fatigue load: (a) initial status, (b) initial debonding degradation $\left(D_{\mathrm{d}}\right.$ due to $\left.P_{\mathrm{d}}, \delta_{d}\right)$, (c) continue debonding degradation $\left(D_{\mathrm{d}}\right)$ at $\delta<\delta_{d}<$ $\delta_{f 0},(\mathrm{~d})$ pin fully debonded and experiencing frictional degradation $\left(D_{\mathrm{f}}\right)$.

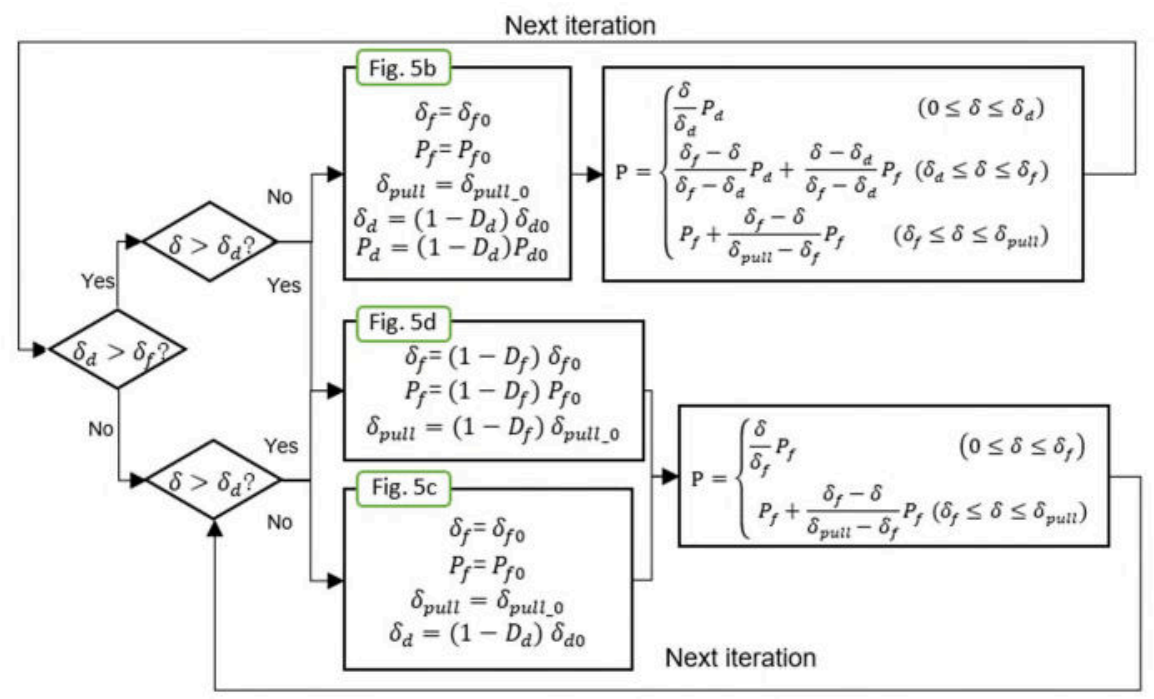

Fig. 6 Calculation procedure of pin's bridging law under fatigue loading, where $\delta$ and $P$ are the current crack opening displacement and bridging force acting on a pin row.

It is worth noting that this model does not account for the effect of pin breakage. The pin breakage mechanism under fatigue is complicated as the degradation of residual shear properties requires further investigation. However, the effect of pin breakage on fatigue life found in our studies (Fig. 11b, Group 2 specimens) is only noticeable at the early stage of the fatigue testing and is negligible after 10,000 cycles. Since these pins were subjected to relatively large crack opening displacement, they typically suffered rapid degradation, i.e. pin's frictional 
pull-out mode was dominant, reducing the pin bridging force by 60-70\% after 1000 cycles. Thus, whether the pin breakage occurred or not, their contribution to the fatigue resistance in the later stage (i.e. after 10,000 cycles) is insignificant.

\section{Experimental}

\subsection{Materials and specimens}

Since the fitting parameters for the proposed pin force degradation law are based on the experimental results from $[16,26]$, similar pin and laminate materials and manufacturing methods were selected for this study. Pinned DCB specimens were fabricated using carbon fibre and epoxy prepreg AS7/8552 with a unidirectional (UD) layup of [0] 24 . The specimen geometry is shown in Fig. 7 and the material properties are given in Table 3. During the specimen fabrication, a release film of $50 \mathrm{~mm}$ length was inserted at the mid-plane to create an initial delamination crack between the adherends.

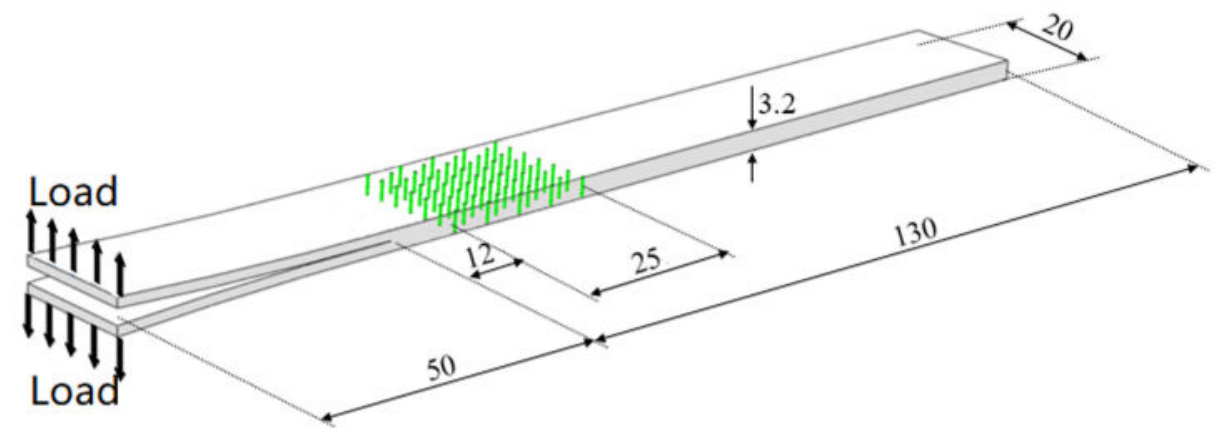

Fig. 7 Geometry and dimension of z-pinned DCB specimen for both static and fatigue tests

The z-pins were made of carbon fibre-bismaleimide (BMI). The pinned region is $25 \mathrm{~mm}$ long, covering the specimen width, and is $12 \mathrm{~mm}$ from the initial crack tip. The pin diameter is $0.51 \mathrm{~mm}$, with a pin pitch distance of $3.2 \mathrm{~mm}$, resulting in the pin areal density of $2 \%$. The pins were inserted through the uncured laminate by an ultrasonically assisted pinning (UAZ) process. The specimens were then autoclave cured under the following conditions; ramp to $110^{\circ} \mathrm{C}$ at $3^{\circ} \mathrm{C} / \mathrm{min}$, hold for 60 minutes, ramp to $180^{\circ} \mathrm{C}$ at $3^{\circ} \mathrm{C} / \mathrm{min}$, hold for 120 minutes, ramp to $60^{\circ} \mathrm{C}$ 
at $5^{\circ} \mathrm{C} / \mathrm{min}$ (nominal 7 bar pressure during cure).

To characterize the single pin mode-I bridging law, a sample with a $6 \times 6$ pin array was manufactured for the pin pull-out test (Fig. 8). The z-pins and laminate were made of the same materials as for the DCB specimens. The specimen was $30 \mathrm{~mm} \times 30 \mathrm{~mm}$ with a thickness of 3.2 mm. A through-thickness tensile test was conducted (i.e. the pin pull-out test) and the load measured from the test was then divided by the total number of pins in the specimen (36) to determine the average single pin traction load.

Table 3 Material properties and Paris law constants of AS7/8552 [24]

\begin{tabular}{lllllll}
\hline$E_{11}(\mathrm{GPa})$ & $E_{22}=E_{33}(\mathrm{GPa})$ & $G_{12}=G_{13}(\mathrm{GPa})$ & $v_{12}=v_{13}$ & $G_{I C}\left(\mathrm{~J} / \mathrm{m}^{2}\right)$ & $C$ & $m$ \\
\hline 145 & 10 & 5 & 0.34 & 280 & $6.0 \mathrm{E}-34$ & 13.14 \\
\hline
\end{tabular}

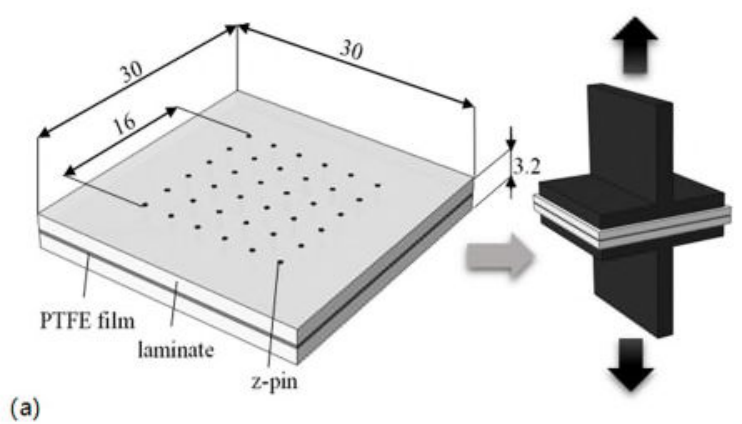

(b)

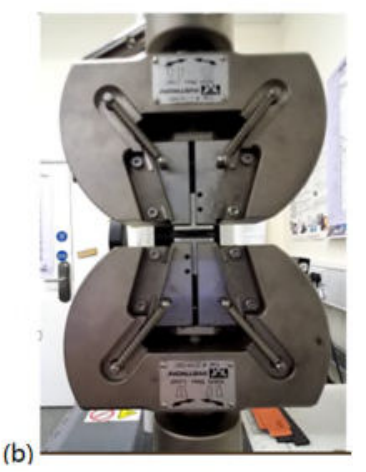

Fig. 8 Mode I pin pull-out test, (a) specimen, (b) specimen in mounting jigs and test machine

\subsection{Test method}

Table 4 summarizes the tests performed in this work. Static load tests of pinned DCB specimens and pin pull-out tests were conducted on a $50 \mathrm{kN}$ electro-servo mechanical machine (Instron 3369) under a displacement controlled loading rate of $1 \mathrm{~mm} / \mathrm{min}$ and $0.5 \mathrm{~mm} / \mathrm{min}$, respectively. Fatigue tests for pinned DCB specimens were conducted under displacement controlled loading at a frequency of $3 \mathrm{~Hz}$ and cyclic load ratio of 0.1 . Two groups of fatigue tests were conducted, 
in which the applied cyclic displacement amplitude was either $80 \%$ or $90 \%$ of the maximum displacement under the static load test $\left(d_{\text {Pmax }}\right)$. Three samples were tested for each test condition. To minimize the thickness effect on crack growth rate, specimens with half specimen thickness of $1.70 \pm 0.02 \mathrm{~mm}$ were selected for the fatigue testing.

Table 4 Summary of experimental tests conducted in this study

\begin{tabular}{|c|c|c|c|c|c|c|}
\hline Specimen & Load & Test condition & $\begin{array}{l}\text { No. of } \\
\text { tests }\end{array}$ & $\begin{array}{l}\text { Loading rate } \\
\text { / Frequency }\end{array}$ & Specimen No. & $\begin{array}{l}\text { Half thickness } \\
(\mathrm{mm})\end{array}$ \\
\hline Pin pull-out & Static & Displacement control & 3 & $0.5 \mathrm{~mm} / \mathrm{min}$ & $\mathrm{SP} 1, \mathrm{SP} 2, \mathrm{SP} 3$ & $1.68-1.85$ \\
\hline Pinned DCB & Static & Displacement control & 3 & $1 \mathrm{~mm} / \mathrm{min}$ & $\mathrm{S} 1, \mathrm{~S} 2, \mathrm{~S} 3$ & $1.62-1.78$ \\
\hline Pinned DCB & Fatigue & $\begin{array}{l}\text { Max disp. } 22.7 \mathrm{~mm} \\
\left(80 \% d_{\mathrm{Pmax}}\right)\end{array}$ & 3 & $3 \mathrm{~Hz}$ & $\begin{array}{l}\text { F1-1, F1-2, } \\
\text { F1-3 }\end{array}$ & $1.70 \pm 0.02$ \\
\hline Pinned DCB & Fatigue & $\begin{array}{l}\text { Max disp. } 25.7 \mathrm{~mm} \\
\left(90 \% d_{\mathrm{P} \max }\right)\end{array}$ & 3 & $3 \mathrm{~Hz}$ & $\begin{array}{l}\text { F2-1, F2-2, } \\
\text { F2-3 }\end{array}$ & $1.70 \pm 0.02$ \\
\hline
\end{tabular}

\section{Results and discussion}

\subsection{Pin pull-out tests under static load}

The compliance of the test machine and deformation of the tab-to-specimen adhesive bond layer are excluded by conducting separate compliance tests. The load vs. displacement curves of three tests of the pin pull-out are shown in Fig. 9. Specimens SP1 and SP3 showed simular behaviour that can be represented by a tri-linear bridging law, whereas specimen SP2 exhibited higher frictional traction force after the pin debonded. Post test observation has revealed that pins in SP2 had relatively larger misalignment, which effectively increased the average embedded length and induced a transition from the mode I to mode II, and thus led to the increased traction force. 


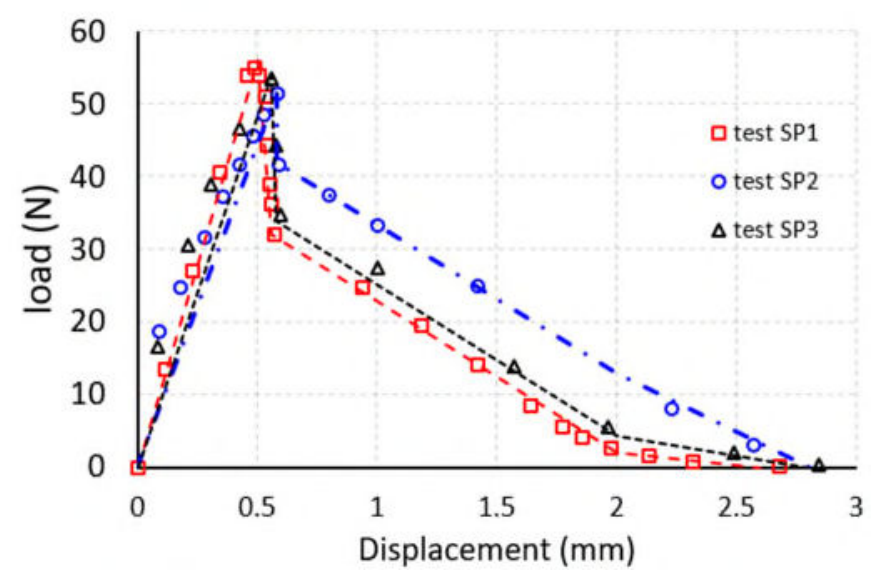

Fig. 9 Measured load vs. displacement curves from experimental pin pull-out testing

\subsection{Fatigue tests and prediction results of z-pinned DCB}

To validate the proposed prediction method, two groups of specimens were tested; each was subjected to a specified cyclic displacement (Group 1 at $80 \%$ of the maximum displacement of the static load test, $0.8 d_{\mathrm{Pmax}}$, and Group 2 at $90 \%, 0.9 d_{\mathrm{Pmax}}$ ).

For Group 1, predicted upper and lower bounds of crack growth rate are compared with test data in Fig. 10a. It demonstrates good coverage of the model of all three test results (F1-1, F12 and F1-3). Crack length vs. cycle number is plotted in Fig. 10b. Resistance to crack growth by the pins was gradually enhanced and the full benefit of z-pinning was reached at the crack length of $30 \mathrm{~mm}$, by which point a large-scale bridging zone was completely established. For all three tests, a stable fatigue crack growth rate was found at about $4.5 \times 10^{-6} \mathrm{~mm} / \mathrm{cycle}$, which is very close to the lower bound of the prediciton (Fig. 10a). This suggests that the predicted "perfect pin case" only slightly underestimates the stable crack growth rate. Since this group was tested under relatively smaller displacement, pins mainly experienced the debonding degradation as discussed in Section 2.4.

For Group $2\left(0.9 d_{\mathrm{Pmax}}\right)$ predicted results and experimental test results are shown in Fig. 11 . The larger applied displacement caused the pins to fully debond at an earlier stage, therefore the 
frictional degradation was dominant. Consequently, specimens failed before the crack growth rate reached a stable value. Specimens F2-1 and F2-2 experienced a faster crack propagation period when the crack reaches 30-35 mm, compared to the predicted upper bounds (i.e highest predicted crack growth rate). This is mostly due to fracture of the misaligned pins before complete degradation (which is expected if the pins were subjected to relatively large applied displacements). The failure mechanism is discussed in more detail in the following section.
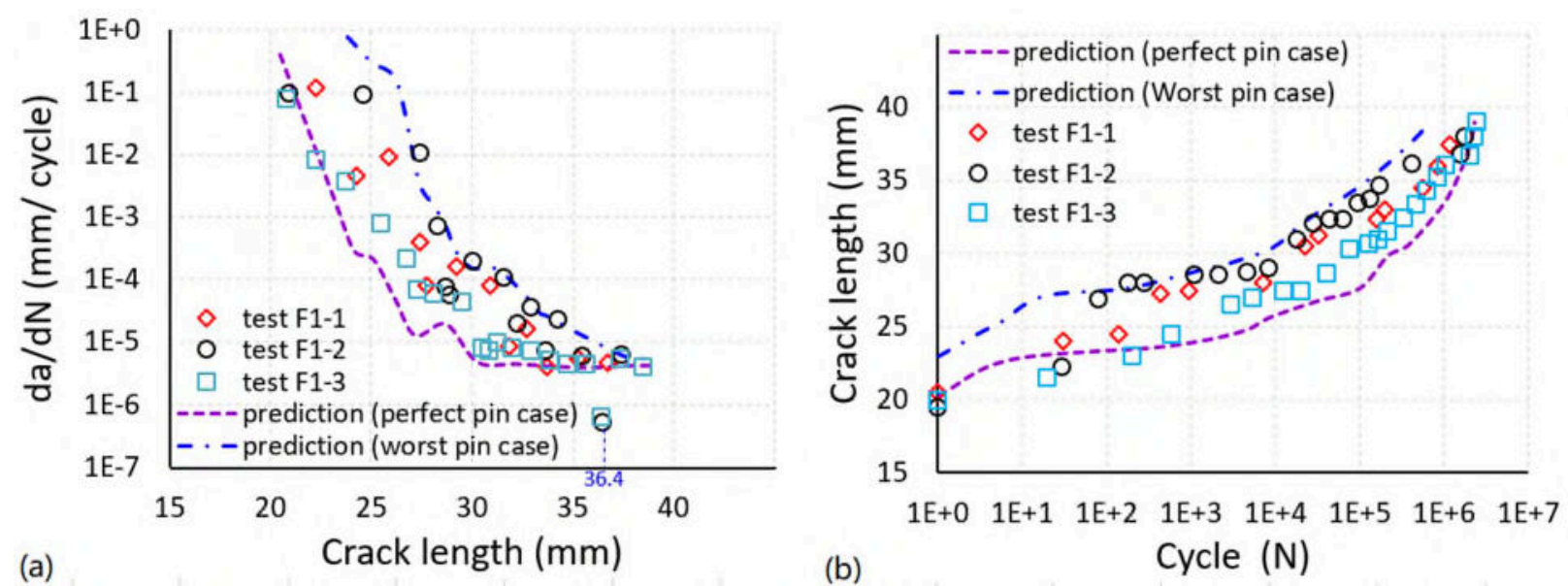

Fig. 10 Group 1 ( $\left.0.8 d_{\mathrm{Pmax}}\right)$ : experimental test and prediction under maximum applied displacement of $22.7 \mathrm{~mm}$ : (a) fatigue crack growth rate vs. crack length, (b) crack length vs. load cycles.
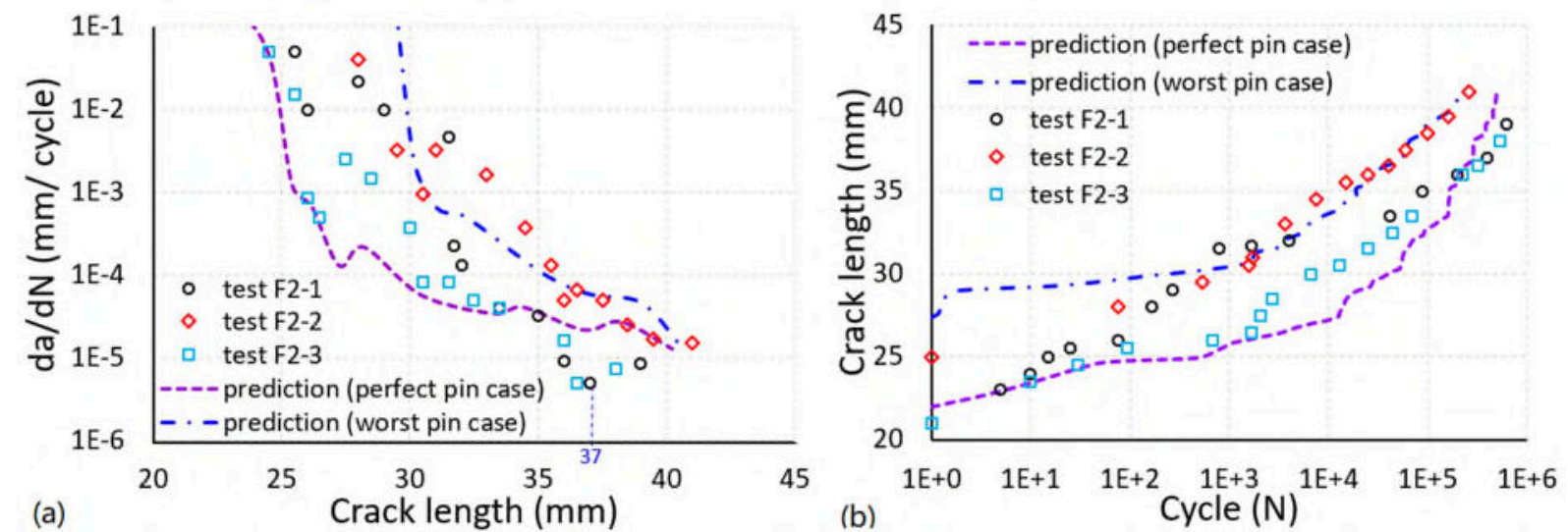

Fig. 11 Group $2\left(0.9 d_{\mathrm{Pmax}}\right)$ : experimental test and prediction under maximum applied displacement of $25.7 \mathrm{~mm}$ : (a) fatigue crack growth rate vs. crack length, (b) crack length vs. load cycles

\subsection{Discussion of pin bridging zone}

The difference in fatigue response between the Group $1\left(0.8 d_{\mathrm{Pmax}}\right)$ and Group $2\left(0.9 d_{\mathrm{Pmax}}\right)$ tests 
can be understood by post failure examination. Under smaller applied displacement (Group 1),

Fig. 12a shows that most of the pins in specimen F1-3 were pulled out. In contrast, the first four pin rows of specimen F2-2 (Group 2, under larger applied dispalcement) had experienced pin breakage, Fig. 12b.

The micromechanical behaviour of the pins as the crack propagates can be understood with the help of the finite element model. Fig. 13 shows a typical simulation of the through-thickness stress contours on a deformed DCB specimen (Group 1 test load). The large crack bridging zone behind the crack tip $(a=36 \mathrm{~mm})$ involves pin rows of all stages. During the fatigue crack propagation, each pin row experiences the following four stages:

Stage 0: before the crack tip reaches the first pin row location; all the pins are inactive;

Stage 1: crack tip passes the first pin row; the pins experience elastic stretching and exert a small amount of bridging force;

Stage 2: as the crack propagates further, the first pin row is further behind the crack tip and experiences more elastic stretching and exerts a higher bridging force;

Stage 3: pins are fully debonded from the laminate and exert a small part of the bridging load by frictional pullout action.
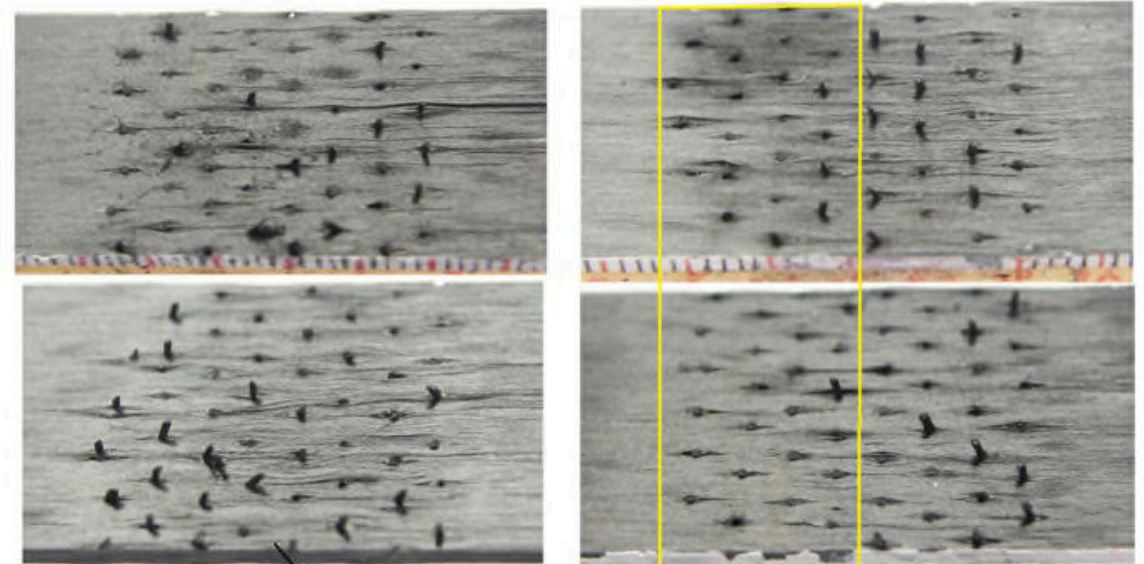

(a)

(b)

Most pin rows were pulled out under smaller applied displacement on DCB specimen.

First four pin rows suffered broken failure mode (rather than pullout) due to larger applied displacement.

Fig. 12 After fatigue failure: (a) specimen F1-3 tested at smaller applied displacement (Group 1, at $0.8 d_{\mathrm{Pmax}}$ ), (b) specimen F2-2 tested at larger applied displacement (Group 2, at $0.9 d_{\mathrm{P} \max }$ ) 


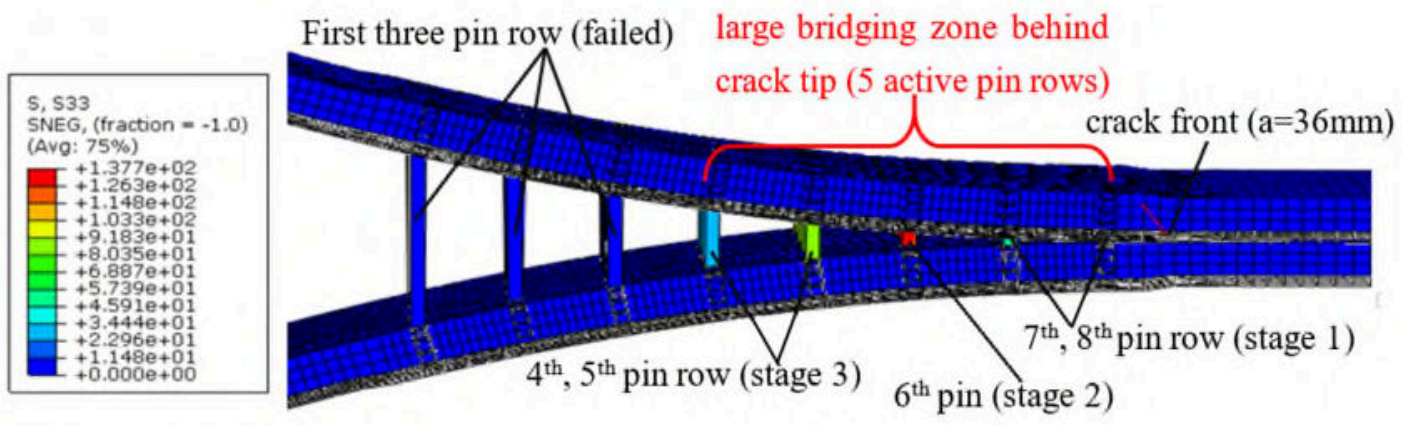

Fig.13 Simulation of a DCB specimen under tension load, showing the first three pin rows in the crack wake (current crack length $36 \mathrm{~mm}$, deformation scale factor 3.0, contour map shows the interlaminar peel stress).

The predicted degradation process of each pin row is presented in Fig.14 based on an FE model using a perfect pin insertion condition. During Stage 1, a relatively small displacement is applied to the debonding degradation law, therefore the degradation process is very slow. When the pins exert higher bridging load (Stage 2), a relatively larger displacement is applied to the debonding degradation law, leading to a moderate degradation rate. After the pins are fully debonded (Stage 3), the frictional degradation law is triggered and the residual peak load decreases rapidly.

In Fig. 14, the crack length corresponding to a specified load cycle number is indicated by a vertical line. At the beginning $(a<24 \mathrm{~mm})$, only three pin rows were activated. Once the crack length has reached $29.8 \mathrm{~mm}$, the number of activated pin rows has gradually increased to a steady state (five pin rows in this case).

This simulation result is consistent with the measured crack growth rate vs. crack length relation (Fig. 10a) for the crack length $a=30 \mathrm{~mm}$, where a stable value of fatigue crack growth rate was reached and maintained. The crack wake maintained a so-called "steady state of pin bridging" zone. As the crack grows beyond $30 \mathrm{~mm}$, for each new pin row that enters the steady state bridging zone, an earlier pin row will fail (i.e. either pins being completely pulled out or broken), 
thus maintanining a maximum of five pin rows in the established bridging zone. It's worth noting that the phenomenon of steady state bridging zone was found in a previous finite element model under static load [28].

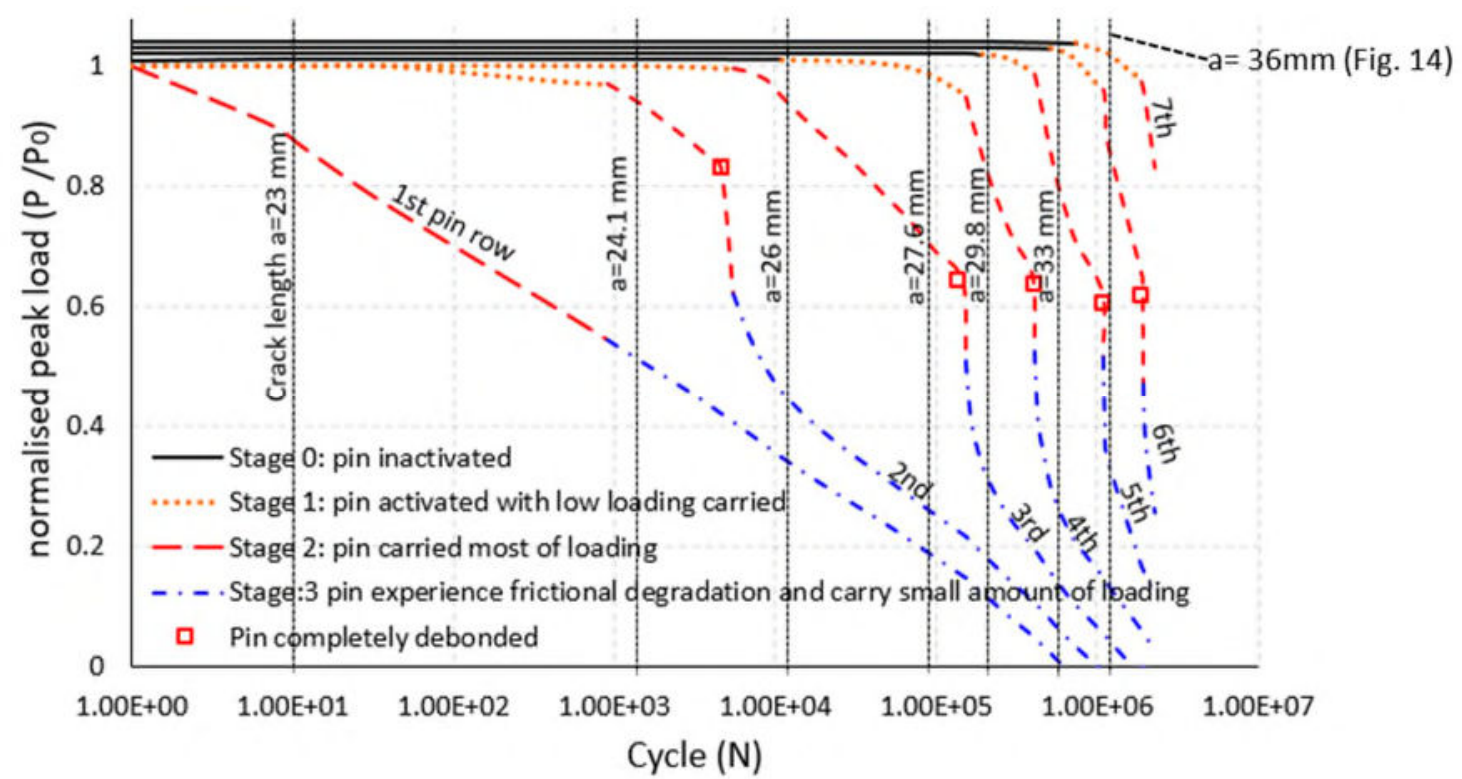

Fig. 14 Simulated bridging force degradation under fatigue loading (Group 1 test, applied displacement at $0.8 d_{\mathrm{Pmax}}$ and assuming perfect pin case)

\subsection{Effect of including debonding behaviour in predictions}

To evaluate the effect of including the debonding phase in fatigue predictions, a predicted lower bound crack growth rate (i.e. perfect pin insertion, which considers only the frictional degradation) was plotted in dotted red line on Fig. 15. The difference in fatigue life between the two prediction methods has gradually increased by 4 times (for applied displacement at 0.8 $d_{\text {Pmax }}$ ) and by 1.8 times (for applied displacement at $0.9 d_{\text {Pmax }}$ ). This suggests that the debonding phase takes up approximately $75 \%$ or $44 \%$ of the total fatigue life at 0.8 or $0.9 d_{\text {Pmax. }}$ It is therefore essential to include the debonding phase in the proposed method to accurately predict the fatigue response over a range of applied displacement amplitudes.

Based on the above discussions, the proposed predictive model has been calibrated and validated with one material system (CFRP laminate and carbon fiber z-pins). Whether the 
degradation rate is dependent on the layup, laminate and pin materials, pin diameter and surface treatment, and pin area density, would require further investigations as the current study on single pin fatigue behavior is very limited (only refs. $[16,26]$ are found in the open literature).

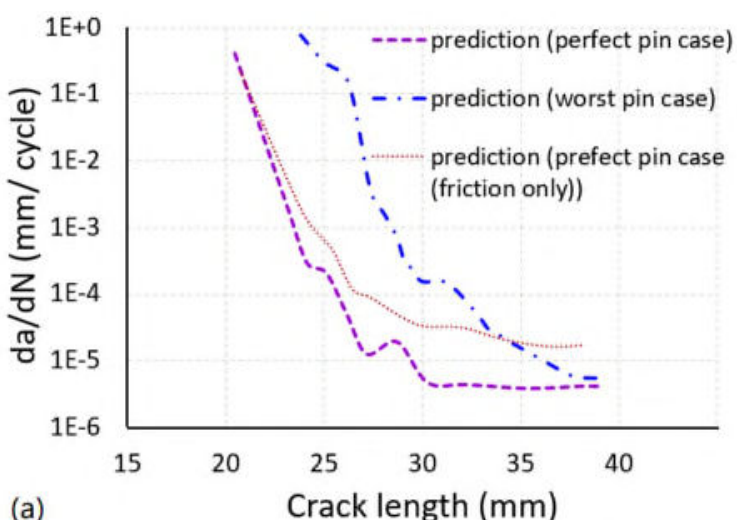

(a)

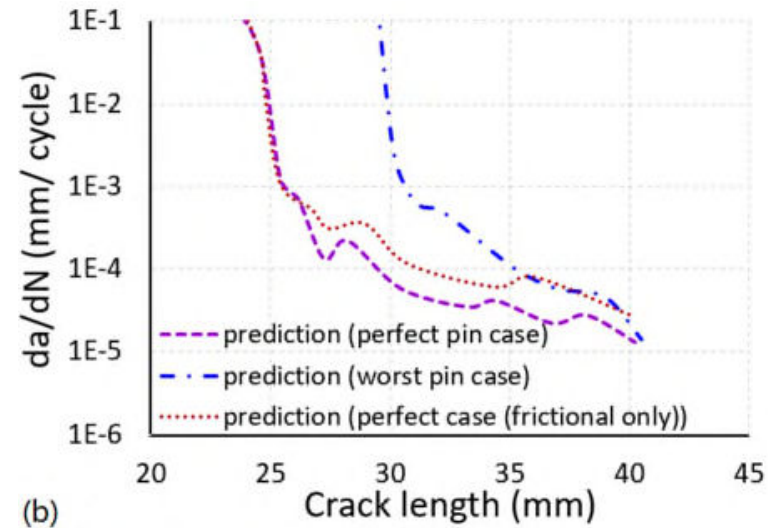

(b)

Fig. 15 Predicted crack growth rate vs. crack length relation: (a) Test Group $1\left(0.8 d_{\text {Pmax }}\right)$, (b) Test Group $2\left(0.9 d_{\mathrm{Pmax}}\right)$

\section{Conclusions}

A method for predicting the fatigue crack growth life of z-pin reinforced composite laminates under mode I loading has been developed and applied to a pin-reinforced double cantilever beam under displacement controlled cyclic loading.

An empirical degradation law based on a damage mechanics approach is proposed to describe the reduction of bridging force experienced by each pin row under cyclic loading. This law can account for damage accumulation at each pin row as it is subjected to different displacement amplitude when the crack tip moves past the pin row. The pins' bridging law is fully defined by assuming that the frictional peak load and displacement will only be degraded when the pin is fully debonded. Results show that fatigue life is underestimated if only the frictional behavior is considered. This demonstrates the importance of incoporating the pin debonding behaviour in any fatigue prediction. Crack growth predictions show good agreement with test results in 
terms of the crack length vs. fatigue life and fatigue crack growth rate vs. crack length relations under two different applied displacements (i.e. $80 \%$ or $90 \%$ of the maximum displacement at static failure).

\section{References}

[1] Cartié DDR, Troulis M, Partridge IK. Delamination of z-pinned carbon fibre reinforced laminates. Compos Sci Technol 2006;66:855-61

[2] Koh TM, Feih S, Mouritz AP. Experimental determination of the structural properties and strengthening mechanisms of z-pinned composite T-joints. Compos Struct 2011;93:2269-76 [3] Dai S-C, Yan W, Liu H-Y, Mai Y-W. Experimental study on z-pin bridging law by pullout test. Compos Sci Technol 2004;64:2451-2457

[4] Zhang X, Hounslow L, Grassi M. Improvement of low-velocity impact and compressionafter-impact performance by z-fibre pinning. Compos Sci Technol 2006;66:2785-94

[5] Cox BN, Shidhar N. A traction law for inclined fibre tows bridging mixed-mode cracks. Mech Adv Mater Struct 2002;9:299-331

[6] Allegri G, Zhang X. On the delamination and debond suppression in structural joints by Zfibre pinning, Compos Part A Appl Sci Manuf 2007;38:1107-1115

[7] Allegri G, Yasaee M, Partridge I, Hallett S, 2014. A novel model of delamination bridging via Z-pins in composite laminates. Int. J. Solids Struc 2014;51:3314-3332

[8] Yan W, Liu HY, Mai YW. Numerical study on the mode I delamination toughness of Zpinned laminates. Compos Sci Technol 2003;63:1481-93

[9] Ratcliffe JG, O'Brien TK. Discrete spring model for predicting delamination growth in Zfiber reinforced DCB specimens. NASA/ TM-2004-213019

[10] Bianchi F, Zhang X. A cohesive zone model for predicting delamination suppression in zpinned laminates. Compos Sci Technol 2011;71:1898-907

[11] Bianchi F, Zhang X, Predicting mode-II delamination suppression in z-pinned laminates, Compos Sci Technol 2012;72:924-932

[12] Cui H, Li Y, Koussios S, Zu L, Beukers A. Bridging micromechanisms of Z-pin in mixed mode delamination. Compos Struct 2011;93(11):2685-95.

[13] Grassi M, Cox BN, Zhang X, Simulation of pin-reinforced single-lap composite joints, Compos Sci Technol 2006;66:1623-1638.

[14] Bianchi F, Koh TM, Zhang X, Partridge IK, Mouritz AP. Finite element modelling of zpinned composite T-joints, Compos Sci Technol 2012;73:48-56

[15] Mohamed G, Allegri G, Yasaee M, Stephen R. Hallett, Cohesive element formulation for z-pin delamination bridging in fibre reinforced laminates, Int. J. Solids Struc 2017;1-13

[16] Zhang AY, Liu HY, Mouritz AP, Mai YW. Experimental study and computer simulation 
of z-pin reinforcement under cycle fatigue. Compos Part A Appl Sci Manuf 2008;39:406-14. [17] Pingkarawat K, Mouritz AP. Improving the mode I delamination fatigue resistance of composites using z-pins. Compos Sci Tech 2014;92:70-6.

[18] Pingkarawat K, Mouritz AP. Comparative study of metal and composite z-pins for delamination fracture and fatigue strengthening of composites. Eng Fract Mech 2016;154:180-90.

[19] Pegorin F, Pingkarawat K, Mouritz AP. Comparative study of the mode I and mode II delamination fatigue properties of z-pinned aircraft composites. Mater Des 2015;65:139-46. [20] Pegorin F, Pingkarawat K, Daynes S, Mouritz AP. Mode II interlaminar fatigue properties of z-pinned carbon fibre reinforced epoxy composites. Compos Part A Appl Sci Manuf 2014;67:8-15.

[21] Pegorin F, Pingkarawat K, Daynes S, Mouritz AP. Influence of z-pin length on the delamination fracture toughness and fatigue resistance of pinned composites. Compos Part B Eng 2015;78:298-307.

[22] Ko MG, Kweon JH, Choi JH. Fatigue characteristics of jagged pin-reinforced composite single-lap joints in hygrothermal environments. Compos Struct 2015;119:59-66.

[23] Pegorin F, Pingkarawat K, Mouritz AP, Mixed-mode I/II delamination fatigue strengthening of polymer composites using z-pins, Compos Part B Eng 2017;123:219-226.

[24] Chen Y, Liu W, Mixed mode delamination static and fatigue crack growth of unidirectional CFRP composite laminates, Cranfield University MSc thesis, 2015. [25] Peerlings RHJ, Brekelmans WAM, De Borst R, Geers MGD, Gradient-enhanced damage modelling of high-cycle fatigue, Int J Numer Meth Engng 2000;49:1547-1569.

[26] Warzok F, Allegri G, Gude M, Hallett S.R, Experimental characterisation of fatigue damage in single Z-pins, Compos Part A Appl Sci Manuf 2016;91:461-471.

[27] Auto2Fit version 5.5, (C) 7D-software, 2010.

[28] Grassi M, Zhang X, Finite element analyses of mode I interlaminar delamination in zfibre reinforced composite laminates. Compos Sci. \& Tech. 63(2003) 1815-1832 
2019-02-13

\section{Fatigue life prediction of z-fibre pinned composite laminate under mode I loading}

Tang, Suchao

Elsevier

Tang S, Lernanski S, Zhang X, Ayre D. (2019) Fatigue life prediction of z-fibre pinned composite laminate under mode I loading. Composites Science and Technology, Volume 174, April 2019, pp. 221-231

https://doi.org/10.1016/j.compscitech.2019.02.010

Downloaded from Cranfield Library Services E-Repository 